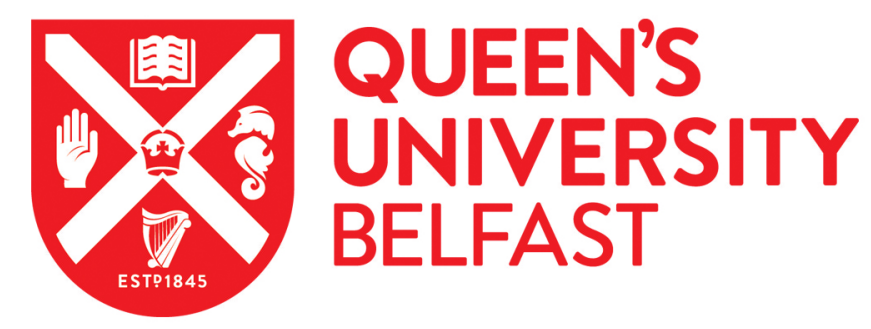

\title{
Impact of fractionation on out-of-field survival and DNA damage responses following exposure to intensity modulated radiation fields
}

Ghita, M., Coffey, C. B., Butterworth, K. T., McMahon, S. J., Schettino, G., \& Prise, K. M. (2016). Impact of fractionation on out-of-field survival and DNA damage responses following exposure to intensity modulated radiation fields. Physics in Medicine and Biology, $61(2), 515-526$. https://doi.org/10.1088/0031-9155/61/2/515

Published in:

Physics in Medicine and Biology

Document Version:

Peer reviewed version

Queen's University Belfast - Research Portal:

Link to publication record in Queen's University Belfast Research Portal

Publisher rights

(C) 2016 Institute of Physics and Engineering in Medicine

\section{General rights}

Copyright for the publications made accessible via the Queen's University Belfast Research Portal is retained by the author(s) and / or other copyright owners and it is a condition of accessing these publications that users recognise and abide by the legal requirements associated with these rights.

Take down policy

The Research Portal is Queen's institutional repository that provides access to Queen's research output. Every effort has been made to ensure that content in the Research Portal does not infringe any person's rights, or applicable UK laws. If you discover content in the Research Portal that you believe breaches copyright or violates any law, please contact openaccess@qub.ac.uk. 
Impact of fractionation on out-of-field survival and DNA damage responses following exposure to intensity modulated radiation fields

Mihaela Ghita $^{1}$, Caroline B. Coffey ${ }^{2}$, Karl T. Butterworth ${ }^{1}$, Stephen J. McMahon ${ }^{1,4}$, Giuseppe Schettino $^{3}$ and Kevin M. Prise ${ }^{1}$

${ }^{1}$ Centre for Cancer Research and Cell Biology, Queen's University Belfast, 97 Lisburn Road, BT7 9AE, Belfast, UK

${ }^{2}$ Department of Pharmacology, School of Medicine, University of Nevada, Reno 89557 USA

${ }^{3}$ National Physics Laboratory, Teddington, TW11 0LW, London, UK

${ }^{4}$ Department of Radiation Oncology, Massachusetts General Hospital and Harvard Medical School, Boston, MA 02114, USA

Short title: Out-of-field responses to dose fractionation

Keywords: Out-of-field effects, dose fractionation, cell survival, DNA damage;

Corresponding author: Mihaela Ghita Centre for Cancer Research and Cell Biology, Queen's University Belfast, 97 Lisburn Road, Belfast BT7 9AE, Northern Ireland, United Kingdom, Tel: +44 (0) 28 90972805, E-mail: m.ghita@qub.ac.uk 


\begin{abstract}
To limit toxicity to normal tissues adjacent to the target tumour volume, radiotherapy is delivered using fractionated regimes whereby the total prescribed dose is given as a series of sequential smaller doses separated by specific time intervals. The impact of fractionation on out-of-field survival and DNA damage responses was determined in AGO-1522 primary human fibroblasts and MCF-7 breast tumour cells using uniform and modulated exposures delivered using a $225 \mathrm{kVp}$ X-ray source. Responses to fractionated schedules (two equal fractions delivered with time intervals from $4 \mathrm{~h}$ to $48 \mathrm{~h}$ ) were compared to those following acute exposures. Cell survival and DNA damage repair measurements indicate that cellular responses to fractionated non-uniform exposures differ from those seen in uniform exposures for the investigated cell lines. Specifically, there is a consistent lack of repair observed in the out-of-field populations during intervals between fractions, confirming the importance of cell signalling to out-of-field responses in a fractionated radiation schedule, and this needs to be confirmed for a wider range of cell lines and conditions.
\end{abstract}




\section{Introduction}

The differential radiobiological responses displayed by normal and tumor tissues exemplified by the five R's of radiotherapy (Asur et al 2013), have led to the development of fractionated radiotherapy protocols where treatments are delivered as a series of equally sized fractions over a period of weeks. These treatment schedules are based largely on empirical observations and are currently being challenged as both hypo- and hyperfractionated schedules become increasingly common practice.

Concurrently, there have been significant technological developments which have improved the conformality of dose to the tumor target whilst reducing dose in nearby normal tissue(Joiner and van der Kogel 2009). As a consequence, some areas outside of the primary treatment fields may experience steep dose gradients while others may receive a non-trivial dose bath due to scattered photons from multiple beams.

Advanced radiotherapy techniques are currently being developed considering the spatiotemporal changes which can affect the biological outcome. Incorporation of these radiobiological responses into the treatment planning to further improve treatment control demands new translational input.

Radiation induced bystander signalling has been observed in a range of cell lines, tissue models and in vivo (Mancuso et al 2008) with an important characteristic being the dose-response relationship. It has been reported that the signal becomes saturated at a relatively low dose of irradiation (commonly below 1 Gy delivered to the target cells) and in many models, the low dose bystander response has been found to be almost equally effective as that of direct irradiation (Prise and O'Sullivan 2010, Mothersill and Seymour 2004).

There have been extensive reports for the importance of bystander effects in vitro (Liu et al 2006, Schettino et al 2005, Butterworth et al 2011) using for example precise microbeam approaches to selectively irradiate specific cells. More recently, experimental studies have 
investigated signalling effects using intensity modulated deliveries from medical linear accelerators (Suchowerska et al 2005, Mackonis et al 2007). Previous work (Ebert et al 2010, McMahon et al 2013a) has suggested that these effects are relevant not only out-of-field, but also contribute to survival of directly irradiated cells, emphasizing their relevance not only to organs at risk but also in tumour volumes.

A recent model (McMahon et al 2013b) shows the predicted clinical relevance of intercellular communication in treatment planning by incorporating bystander signalling as part of the biological effective dose. The model predicts a significant difference in the signalling adjusted dose and physical dose for a large volume, with the highest impact for nearby organs at risk. Additionally, high dose regions will see a decrease in the biologically effective dose with significant differences (i.e., from 74 to $71 \mathrm{~Gy}$ ) in IMRT plans. However, the model considers the radiation being delivered as a single acute dose and does not consider cell recovery and possible complications due to the intercellular signalling between fractions.

Because of the well-established impact of fractionation in clinical settings and the increasing interest in alternative fractionation schedules, an understanding of the impacts of fractionation on intercellular signalling effects is important to understand the role these effects may have in advanced therapies. This study aims to address this need by determining the impact of dose fractionation on in- and out-of-field responses of DNA damage and survival.

\section{Materials and Methods}

\section{Cell culture}

Experiments were conducted using two human cell lines, the breast adenocarcinoma cell line, MCF-7 and the transformed fibroblast cell line, AGO-1522. Cell lines were selected as malignant and transformed models with previously reported radiosensitivities and alpha/beta ratios. MCF-7 cells, obtained from Cancer Research UK, were maintained in Dulbecco's 
Modified Eagle's Medium (Sigma Aldrich, UK) supplemented with 10\% fetal bovine serum (PAA Laboratories, UK) and 1\% penicillin/streptomycin (Gibco-Invitrogen, UK). AGO-1552 cells obtained from the Coriell Institute for Medical Research (Camden, NJ, USA) and maintained in $\alpha$-modified Eagle's Medium (Lonza, UK) supplemented with $20 \%$ fetal bovine serum (PAA Laboratories, UK) and 1\% penicillin/streptomycin. All cell lines were maintained at $37^{\circ} \mathrm{C}$ in a humidified atmosphere of $5 \% \mathrm{CO}_{2}$.

\section{Clonogenic survival assay}

Cell survival was determined by clonogenic assay as previously described (Trainor et al 2012a). Cells were plated and allowed to adhere overnight before being irradiated with a single, acute exposure or two equally sized fractions separated by time intervals from 4 to 48 hours and incubated at $37^{\circ} \mathrm{C}$ between irradiations. Exposures were performed under uniform and shielded beam configurations. For the more radioresistant MCF-7 cell line, doses between 0-8 Gy were used, while for the more radiosensitive cell line (AGO-1552) doses between 0-6 Gy were used. For each experiment, unexposed controls were prepared and treated as sham exposures. Experiments were conducted under standard culture conditions or in the presence of the free radical scavenger, dimethyl sulphoxide (DMSO, Sigma Aldrich, UK) at a concentration of $5 \%$ in culture media added 2 hours prior to irradiation and removed and replaced with complete culture medium 24 hours after irradiation. Cultures were incubated for 10-14 days before staining with $0.5 \%$ crystal violet in $70 \%$ methanol. 
Cells were plated at a density of $1.5 \times 10^{5}$ cells onto microscope slides in P90 cell culture dishes and allowed to adhere overnight before being irradiated (acute or split exposure) with a total dose of 2 Gy separated by times ranging from 30 minutes to 24 hours. Exposures were performed under uniform and shielded beam configurations and cells fixed using $4 \%$ paraformaldehyde solution at time intervals up to 24 hours. DNA damage was quantified by immunofluorescence detection of $\gamma \mathrm{H} 2 \mathrm{AX}$ and 53BP1 as previously described (Trainor et al 2012b). Nuclear foci were manually scored for 100 cells per slide using a Zeiss Axiovert 200 M microscope (Carl Zeiss MicroImaging, LLC, USA).

\section{Irradiation setup and validation of experimental design}

As cellular responses to radiation exposure are determined by a variety of parameters including cell type, absorbed dose and irradiation time, a variety of irradiation scenarios have been setup on an X-RAD $225 \mathrm{kVp}$ (Precision X-Ray) source with a dose-rate of $0.59 \mathrm{~Gy} / \mathrm{min}$. These included single and fractionated dose deliveries for uniform and shielded exposures.

Each T25 flask (Nunclon surface NUNC) was aligned with the beam centre and for shielded exposures lead shielding (13.6 x $10.4 \times 2.1 \mathrm{~cm}^{3}$ lead blocks MCP60-Mining \& Chemical Products Ltd.) was positioned over half of the dish or flask, $2.8 \mathrm{~cm}$ above the cell layer. RTQA Gafchromic $^{\circledR}$ film (Vertec Scientific Ltd.) was attached to the bottom of each flask in order to help repositioning the flask and monitoring the dose boundaries. When scoring the foci or colonies, an exclusion zone of $1 \mathrm{~cm}$ was defined around the dose fall-off region (as seen in figure 1). 
Ionisation chamber (PTW Freiburg) measurements were made in conjunction with film measurements to define the shielded and penumbra regions. The dose delivered to the out-offield region was estimated as the average scattered dose to that region. For a 50\% modulated field the scattered dose received out-of-field was determined to be $3 \%$ of the total dose delivered to the in-field region.

\section{Data analysis}

For each of the clonogenic experiments, survival fractions were calculated as the ratio between the number of surviving colonies in the irradiated flask relative to the number of colonies in a sham irradiated flask normalized to the number of cells plated.

The survival curves have been fitted using the linear quadratic model $y=e^{-\alpha D-\beta D^{2}}$ where the $\alpha D$ term represents cell death due to complex single event hits, and $\beta D^{2}$ is attributed to multiple track events; the out-of-field survival was fitted using a single exponential function $y=y_{o}+$ $A e^{-a d}$ where $d$ is the scattered dose under the shielding. Recovery kinetics for 8 and 6 Gy doses were fitted to the exponential decay function $y=A e^{-t / \lambda}$ where $\lambda$ is the characteristic time.

DNA damage analysis considered foci number relative to sham irradiated control numbers. The onset and repair curve for single dose irradiation was fitted to the following equation $y=A\left(1-e^{-r t}\right) e^{-b t}$, where $t$ is the incubation time after irradiation, $r$ the rate at which foci appear, and $b$ the DNA damage decay rate. The fractionated exposure foci decay curves for uniform field and in-field were fitted to the single phase exponential decay $y=y_{0}+A e^{-b t_{1}}$ where $t_{1}$ is the time interval between the fractions, $y_{0}$ is the number of foci induced by the second fraction, $b$ the damage decay rate and $A$ the number of foci from the first fraction.

All experiments were carried out in duplicate, on at least 3 separate occasions. The data is presented as \pm standard error and corrected for the non irradiated controls. 
Data was fitted using Origin Pro 8.0 and statistical errors are calculated as the standard error of the mean. Statistical analysis for DNA damage experiments was carried out using Student's t-test, and Mann-Whitney $U$ test for cell survival data. Statistical significant differences were assumed at the level of $p<0.05$.

\section{Results}

Impact of fractionation on cell survival

As seen in figure 2 both cell lines show an increase in cell survival after the fractionated uniform dose delivery when compared to acute exposure, even at the shortest time intervals (4 hrs). The lack of further repair as inter-fraction time increases indicates repair processes with a short half-time have a stronger impact on the overall survival.

Figures 3 and 4 show the effects of modulated field exposures both in- and out-of-field. The sparing effect on the directly irradiated cells is still present as previously reported for a single fraction (van den Aardweg 2003). The response of the out-of-field cells is independent of dose fractionation, with no evidence for either repair between fractions or a cumulative effect from multiple exposures; this behaviour is consistent in both cell lines.

When using a free radical inhibitor such as DMSO the intercellular effects are abrogated in both cell lines. This is known (McMahon et al 2013a, Trainor et al 2012a) to attenuate the outof-field effects and the survival fraction increases to the one expected for scattered dose alone. This also has effects on the in-field sparing, thus causing the survival fraction in-field to follow a similar trend to the uniform field irradiation. 
As expected, fractionation has a significant effect on the beta component, (as seen in table 1). For AGO-1522, it decreases from $0.023 \mathrm{~Gy}^{-2}$ for acute dose delivery to 0 for split dose irradiation, while $\alpha$ has no significant variation. MCF-7 cells show a decrease in $\beta$ from 0.064 $\mathrm{Gy}^{-2}$ for single dose irradiation to $0.03 \mathrm{~Gy}^{-2}$ for split-dose irradiation. Within experimental uncertainties these observations agree with modelling fractionated exposures as 2 independent single fractions (which predict $\beta$ for two-fraction exposures should be equal to a half that of a single exposure). Similar trends for $\alpha$ and $\beta$ with dose fractionation have been reported elsewhere (van den Aardweg 2003).

DNA damage repair following exposure to fractionated radiation

Figure 5a shows reference DNA repair kinetics for both cell lines for 53BP1 DNA damage marker only following acute exposure with $2 \mathrm{~Gy}$. The residual damage level at $24 \mathrm{~h}$ is $8.3 \pm 1.4$ and 5.6 \pm 0.89 foci per cell linked to a repair half time of $4.52 \pm 0.5$ and $5.92 \pm 0.8 \mathrm{~h}$ for MCF7 and AGO-1522 respectively.

To assess how the inter-fraction time affects the DNA damage, contribution of the second fraction was kept constant by fixing the slides 30 minutes after the last irradiation. Figure $5 \mathrm{~b}$ and $\mathrm{c}$ show the damage decay with half-lives of $4.07 \pm 0.5 \mathrm{~h}$ for MCF7 and $6.93 \pm 0.8 \mathrm{~h}$ for AGO1522. For the same time points in modulated configuration the DNA damage has a half life of $9.9 \pm 0.9 \mathrm{~h}$ for MCF7 and $0.5 \pm 0.12 \mathrm{~h}$ in AGO-1522 cell line (Figure 6). Table 2 shows the variation of the DNA damage decay rates and half-times. It is important to note that the repair half time for uniform field and cell survival data indicate the $4 \mathrm{~h}$ time interval is very important in cell recovery for the investigated cell lines.

In both MCF-7 and AGO-1522 cells, no statistically significant difference was seen in DNA damage levels observed out-of-field with varying inter-fraction times. This suggests that no 
additional DNA damage accumulates after the delivery of the first fraction which is also consistent with the observed cell survival responses.

\section{Discussion}

Previous studies (Butterworth et al 2011, McMahon et al 2013a) highlighted the importance of intercellular signaling in modulated fields, showing that survival of directly irradiated cells depends not only on the physical dose but also on the dose the cells in the vicinity experience. It is clear that both the increase in cell death in the regions outside the primary radiation field and the increase in survival in the directly irradiated cells could have a potential impact in radiotherapy.

Van den Aardweg et.al. (van den Aardweg 2003) investigated the effects of fractionated irradiation in primary and metastatic Human Uveal Melanoma cell lines using the clonogenic survival assay. Similar to the work presented here, the results indicated that fractionation had little influence on the $\alpha$ component. The overall enhancement of cell survival observed with dose fractionation was linked with repair of the sub-lethal DNA damage induced by the first dose, and expressed as the $\beta$ component of the LQ model.

Previous work from Mothersill et.al.(Mothersill and Seymour 2002) used the irradiated cell conditioned medium (ICCM) after fractionated exposure of donor cells to investigate the recovery pattern on recipient cells. Directly irradiated cells showed a significant recovery with dose fractionation, but recipient cells show no recovery with the dose split in two equal fractions by 3 hour time lapse. However, medium harvested from cells exposed to fractionated irradiation and added to non-irradiated cells reduced the survival below that seen for medium harvested from cells irradiated using a single-dose protocol. The authors reported that cells treated with media harvested from fractionated irradiation have a lower level of 'recovery 
factors' than those directly exposed to fractionated irradiation. This is consistent with the results presented here, pointing towards the lack of repair experienced by the out-of-field populations during variable inter-fraction exposure times.

The recovery kinetics observed in this work are in agreement with previous reports (Mariotti et al 2013) showing that cells have largely recovered by 6 hours after the first irradiation event. Consequently, DNA damage induced by the second fraction is not enhanced by any residual damage, and cells react to it as a new single exposure.

While fractionation has a significant effect on uniformly exposed populations, the overall survival is influenced by the intercellular signalling occurring in the modulated field exposures. The out-of-field populations have a different behaviour than the in-field cells at the DNA damage level, but this induces no significant change in the long term survival.

When delivering the dose as two equal fractions, the out-of-field response has, as previously established (Schettino et al 2005), a binary behaviour, with populations of responding and nonresponding cells, reaching saturation at low out-of-field doses $(<0.5 \mathrm{~Gy})$. The lack of variation of the out-of-field responses with the inter-fraction interval suggests that the response is, as previously modelled (McMahon et al 2013a), related to the amount of time the signal is above a threshold value and not to the total signal exposure.

The differing responses to fractionation between in- and out-of-field cells may have a significant impact on biological optimisation of fractionated radiotherapy. The effects of fractionation are typically understood through the partial or complete repair of sublethal damage with some characteristic half-life $\left(\mathrm{T}_{1 / 2}\right)$ (Thames et al 1984).

While these results are in agreement with this assumption for an individual exposure condition, they also suggest that, for the presented cell models, sublethal damage repair kinetics are not solely a function of a cell's intrinsic radiosensitivity, but also on whether it is directly exposed to ionising radiation, subject to bystander stress, or a combination of both effects. This is a 
significant departure from established models, and may need to be incorporated in future radiobiological treatment planning models to fully understand and optimise the therapeutic ratio through parameters such as fraction size and margin prescription.

\section{Conclusion}

The impact of dose fractionation cannot be assessed in isolation but must consider the complex relationship between tumour radiosensitivity and the normal tissue tolerance to the late effects of radiation. The results in this work indicate that conclusions from directly irradiated repair kinetics cannot be extrapolated directly to populations that are primarily exposed to out-offield scattered radiation, as signalling-driven damage has significantly different kinetics. Considering the limitations of the model proposed here, further validation is required for a wider range of cell lines, different conditions, and in vivo, before their incorporation into robust treatment planning models as an important step towards the development of future biologically optimised treatment protocols.

\section{Acknowledgements}

The authors acknowledge the support of Breast Cancer Campaign (2009MayPR03) and Cancer Research UK (C1513/A7047). SJM is the holder of an EU Marie Curie Fellowship (FP7 - MC IOF - 623630).

\section{Conflict of interest statement}

Authors have no conflict of interest. 


\section{References}

Van den Aardweg G J M J 2003 Dose Fractionation Effects in Primary and Metastatic Human Uveal Melanoma Cell Lines Invest. Ophthalmol. Vis. Sci. 44 4660-4 Online:

Asur R, Butterworth K T, Penagaricano J a, Prise K M and Griffin R J 2013 High dose bystander effects in spatially fractionated radiation therapy. Cancer Lett. 356 52-7

Butterworth K T, McGarry C K, Trainor C, O’Sullivan J M, Hounsell A R and Prise K M 2011 Out-of-field cell survival following exposure to intensity-modulated radiation fields. Int. J. Radiat. Oncol. Biol. Phys. 79 1516-22 Online:

Ebert M a, Suchowerska N, Jackson M a and McKenzie D R 2010 A mathematical framework for separating the direct and bystander components of cellular radiation response. Acta Oncol. 49 1334-43

Joiner M and van der Kogel A 2009 Basic clinical Radiobiology ed M Joiner and A van der Kogel (London: Hodder Education, Hachette UK)

Liu Z, Mothersill C E, McNeill F E, Lyng F M, Byun S H, Seymour C B and Prestwich W V 2006 A dose threshold for a medium transfer bystander effect for a human skin cell line. Radiat. Res. 166 19-23

Mackonis E C, Suchowerska N, Zhang M, Ebert M, McKenzie D R and Jackson M 2007 Cellular response to modulated radiation fields. Phys. Med. Biol. 52 5469-82

Mancuso M, Pasquali E, Leonardi S, Tanori M, Rebessi S, Di Majo V, Pazzaglia S, Toni M P, Pimpinella M, Covelli V and Saran A 2008 Oncogenic bystander radiation effects in Patched heterozygous mouse cerebellum. Proc. Natl. Acad. Sci. U. S. A. 105 12445-50 Online:

Mariotti L G, Pirovano G, Savage K I, Ghita M, Ottolenghi A, Prise K M and Schettino G 2013 Use of the $\gamma$-H2AX assay to investigate DNA repair dynamics following multiple radiation exposures. PLoS One $\mathbf{8}$ e79541

McMahon S J, Butterworth K T, Trainor C, McGarry C K, O’Sullivan J M, Schettino G, Hounsell A R and Prise K M 2013a A kinetic-based model of radiation-induced intercellular signalling. PLoS One 8 e54526

McMahon S J, McGarry C K, Butterworth K T, O’Sullivan J M, Hounsell A R and Prise K M 2013b Implications of intercellular signaling for radiation therapy: a theoretical doseplanning study. Int. J. Radiat. Oncol. Biol. Phys. 87 1148-54 
Mothersill C and Seymour C 2004 Radiation-induced bystander effects and adaptive responses--the Yin and Yang of low dose radiobiology? Mutat. Res. 568 121-8

Mothersill C and Seymour C B 2002 Bystander and delayed effects after fractionated radiation exposure. Radiat. Res. 158 626-33

Prise K M and Sullivan J M O 2010 UKPMC Funders Group Radiation-induced bystander signalling in cancer therapy $9351-60$

Schettino G, Folkard M, Michael B D and Prise K M 2005 Low-dose binary behavior of bystander cell killing after microbeam irradiation of a single cell with focused $\mathrm{c}(\mathrm{k}) \mathrm{x}$ rays. Radiat. Res. 163 332-6 Online: http://www.ncbi.nlm.nih.gov/pubmed/15733040

Suchowerska N, Ebert M a, Zhang M and Jackson M 2005 In vitro response of tumour cells to non-uniform irradiation. Phys. Med. Biol. 50 3041-51

Thames H D, Withers H R and Peters L J 1984 Tissue repair capacity and repair kinetics deduced from multifractionated or continuous irradiation regimens with incomplete repair. Br. J. Cancer. Suppl. 6 263-9 Online:

Trainor C, Butterworth K T, Mcgarry C K, Liberante F, Sullivan J M O, Hounsell A R, Sullivan O and Cell K M 2012a Cell Survival Responses after Exposure to Modulated Radiation Fields Radiat. Res. 51 44-51

Trainor C, Butterworth K T, McGarry C K, McMahon S J, O'Sullivan J M, Hounsell A R and Prise K M 2012b DNA damage responses following exposure to modulated radiation fields $P$ LoS One 7 
Figure 1. Schematic diagram of irradiation setup and the dose fall-out region at the field margin for a single fraction. Cells were seeded in T25 flasks and irradiated with the centre of the flask aligned with the shielding edge. Dose profiles were measured by Gafchromic ${ }^{\circledR}$ film at different distances off axis after both fractions were delivered. Exclusion margin is set $1 \mathrm{~cm}$ around the dose fall-off region to account for the dose-step when repositioning the flask.

Figure 2. Impact of dose fractionation on clonogenic survival for MCF-7 (a) and AGO-1522 (c) cells following exposure to a uniform field configuration. Survival was calculated following acute single (solid line LQ fit) and total dose delivered as two equal fractions given $4 \mathrm{~h}, 6 \mathrm{~h}$, $24 \mathrm{~h}$, or $48 \mathrm{~h}$ apart (dashed lines LQ model fit). ${ }^{*} \mathrm{p} \leq 0.05,{ }^{*} \mathrm{p} \leq 0.01$. b) and d) recovery kinetics for 8 and 6 Gy doses for MCF 7 and AGO-1522 respectively as a function of the time interval between deliveries (solid line is the fit according to $y=A e^{-t / \lambda}$ where $\lambda$ is the characteristic repair time). Error bars indicate \pm standard error of the mean, $n=3$.

Figure 3. Impact of dose fractionation on clonogenic survival for MCF-7 in- (a) and out-offield (c) cells following exposure to a modulated field configuration. Survival was calculated following acute single (solid line fit to LQ model) and total dose delivered as two equal fractions given $4 \mathrm{~h}, 6 \mathrm{~h}, 24 \mathrm{~h}$, or $48 \mathrm{~h}$ apart ( dashed line fit to LQ model) $.^{*} \mathrm{p} \leq 0.05,{ }^{*} \mathrm{p} \leq 0.01$. The effect of the addition of the free radical scavenger DMSO for 4 Gy fractionated doses are shown in- and out of field in b) and d) respectively; e) recovery kinetics for 8 Gy in-field survival as a function of the time interval between fractions, solid line is the fit according to 
$y=A e^{-t / \lambda}$ where $\lambda$ is the characteristic repair time. Error bars indicate \pm standard error of the mean, $n=3$.

Figure 4. Impact of dose fractionation on clonogenic survival for AGO-1522 in- (a) and outof-field (c) cells following exposure to a modulated field configuration. Survival was calculated following acute single (solid line fit to LQ model) and total dose delivered as two equal fractions given $4 \mathrm{~h}, 6 \mathrm{~h}, 24 \mathrm{~h}$, or $48 \mathrm{~h}$ apart ( dashed line fit to LQ model) $.^{*} \mathrm{p} \leq 0.05,{ }^{*} \mathrm{p} \leq 0.01$. The effect of the addition of the free radical scavenger DMSO for 4 Gy fractionated doses are shown in- and out of field in b) and d) respectively; e) recovery kinetics for 6 Gy in-field survival as a function of the time interval between fractions, solid line is the fit according to $y=A e^{-t / \lambda}$ where $\lambda$ is the characteristic repair time. Error bars indicate \pm standard error of the mean, $n=3$.

Table 1. $\alpha$ and $\beta$ parameters for AGO-1522 and MCF-7 for uniform field and exposed modulated field. 0h time point corresponds to single dose irradiation. Survival curve for uniform irradiation and modulated in-field were fitted by LQ model.

Figure 5. DNA damage repair kinetics following exposure to a uniform radiation field after single dose (a) 53BP1 kinetics for both cell lines (MCF-7 solid line, AGO-1522 dashed line). Time points represent the incubation time after dose delivery. Kinetics following fractionated dose represented in (b) MCF-7 and (c) AGO-1522 solid line $\gamma \mathrm{H}_{2} \mathrm{AX}$, dashed line 53BP1. Foci numbers are corrected for sham-irradiated controls and a single phase exponential decay was used to fit the data. Time lapse indicates time between fractions; cells were fixed 30 minutes after the last dose delivery. Error bars indicate \pm standard error of the mean, $n=3$. 
Figure 6. DNA damage kinetics for 53BP1 following exposure to a modulated field and fractionated dose for (a) MCF-7 and (b) AGO-1522 cell lines; Solid line represents in-field repair and dotted line out-of-field kinetics. All cells were fixed 30 minutes after the last fraction was delivered. Foci numbers are corrected for sham-irradiated controls and data was fitted using a single phase exponential decay. Error bars indicate \pm standard error of the mean, $\mathrm{n}=3$

Table 2. Fitting parameters for DNA damage decay curve for single dose uniform field and fractionated dose uniform and modulated fields. Supplementary table 2A contains the fitting parameters used in figure $4 \mathrm{a}$. Table $2 \mathrm{~B}$ shows the decay rates for DNA damage for $2 \mathrm{~Gy}$ delivered as two equal fractions in uniform field or shielded configurations (Fig $5 \mathrm{~b}$ and $\mathrm{c}$ and Fig 6). 


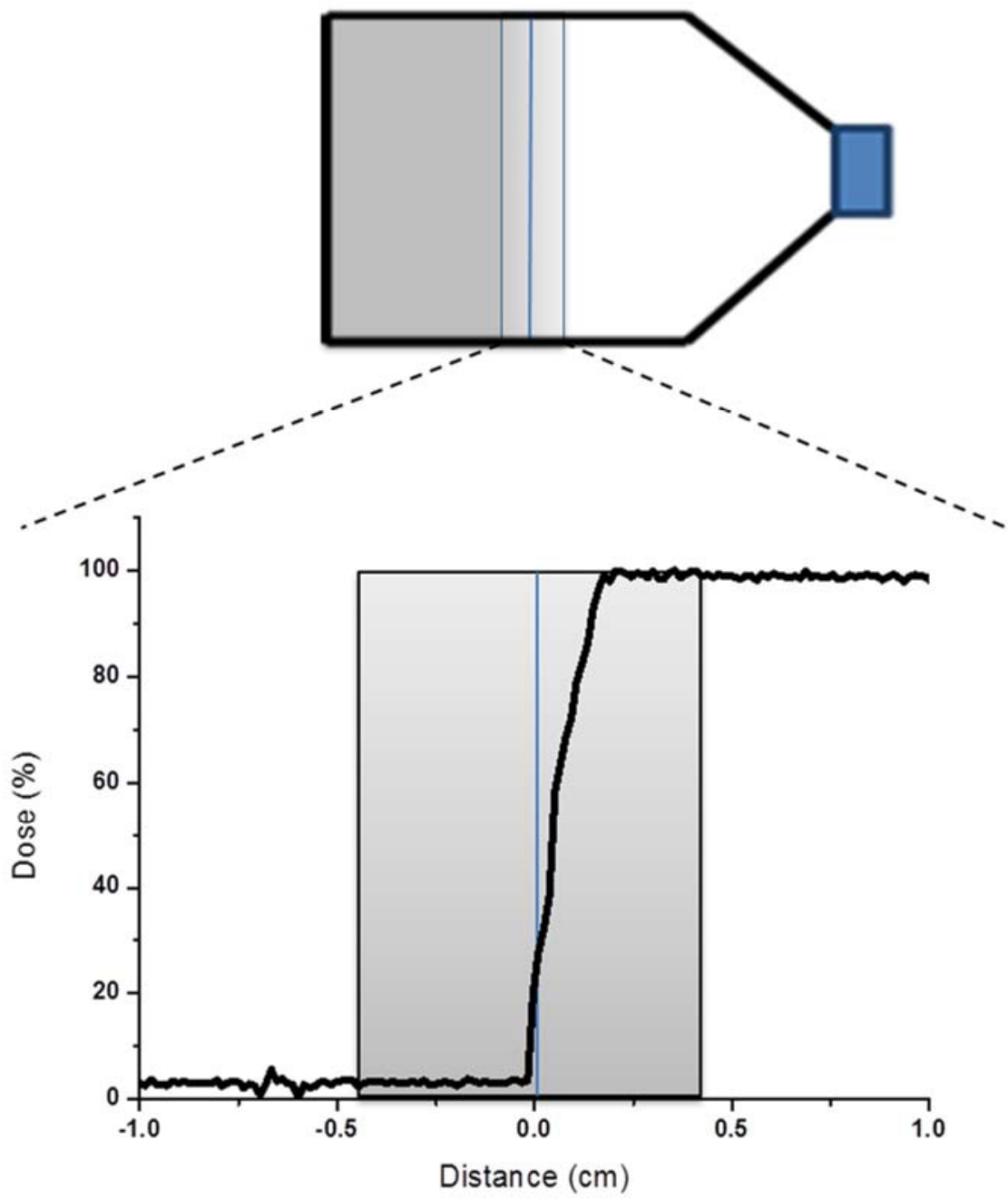

Figure 1. 


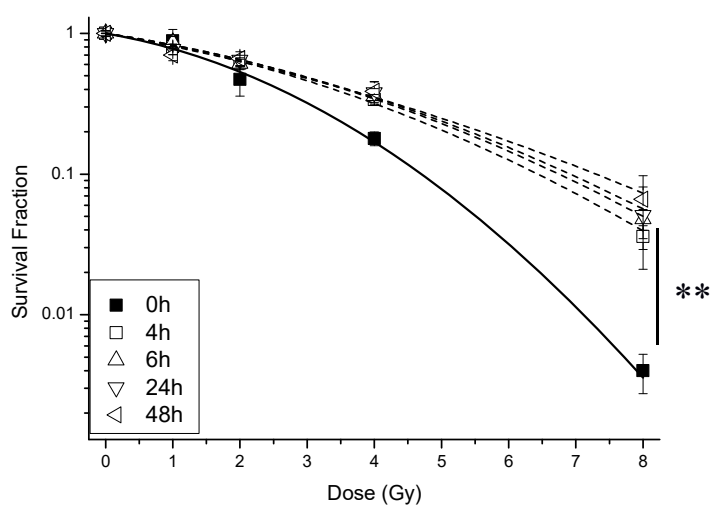

A

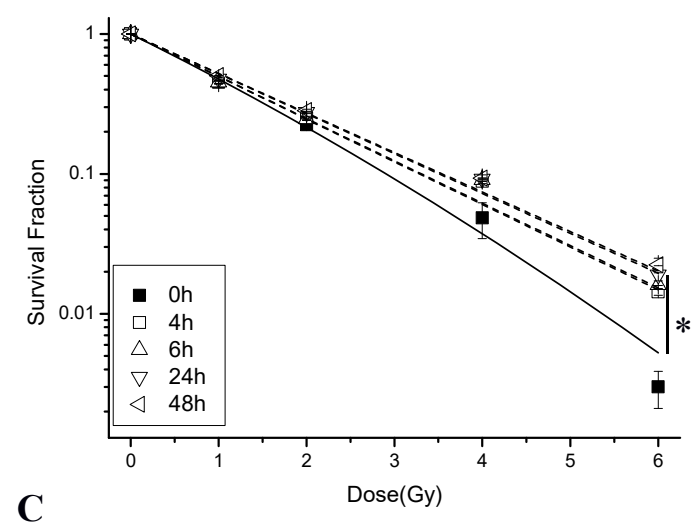

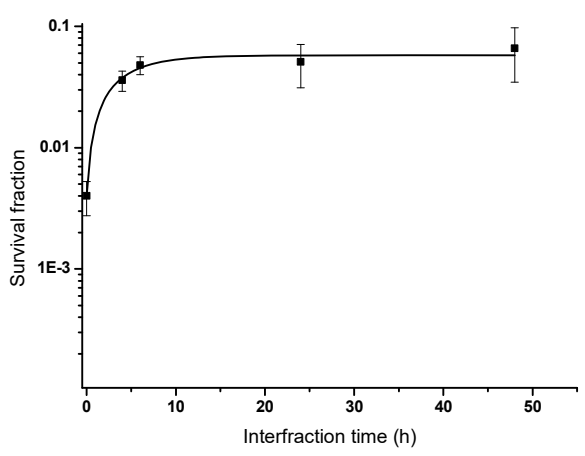

B

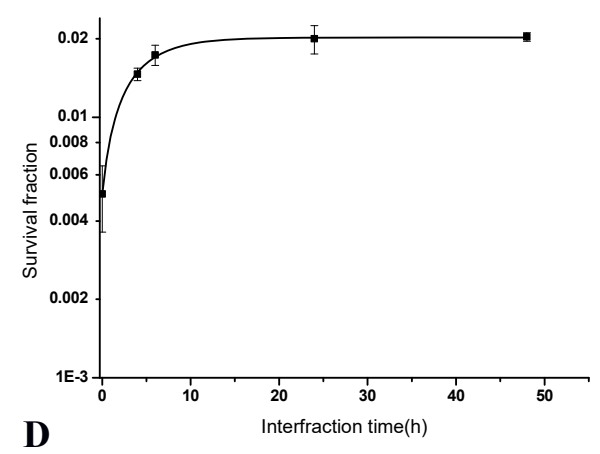

Figure 2. 

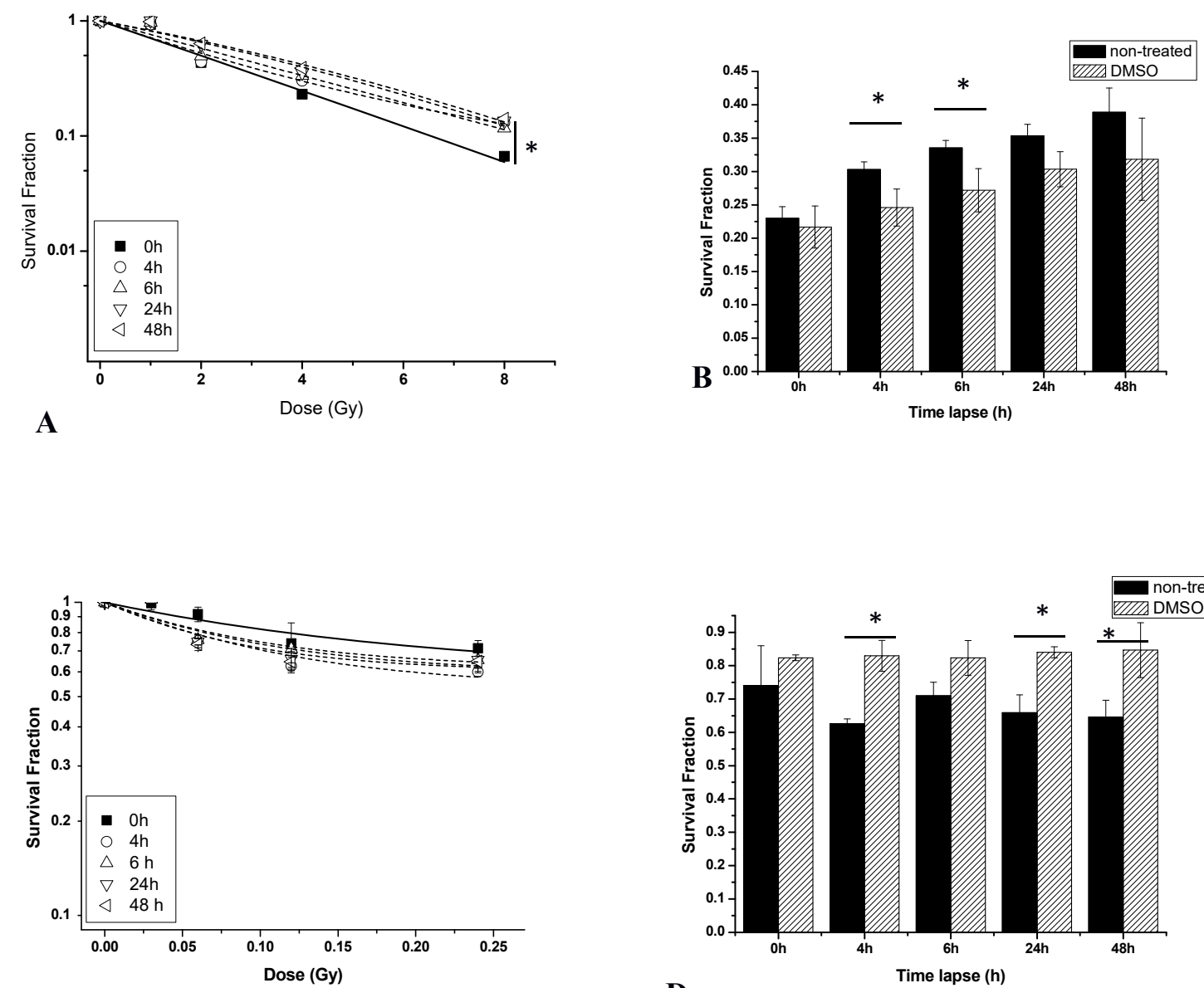

C
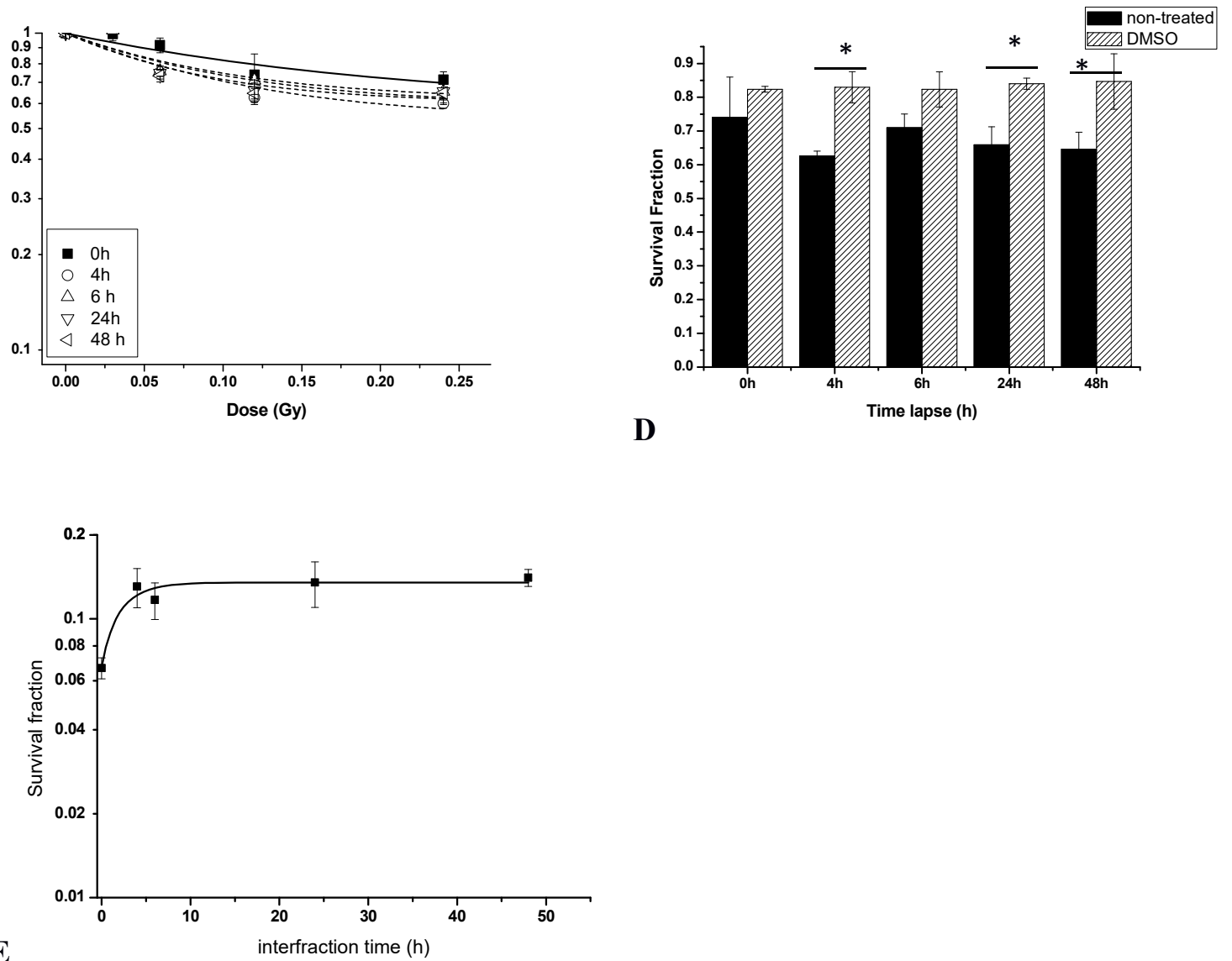

Figure 3. 

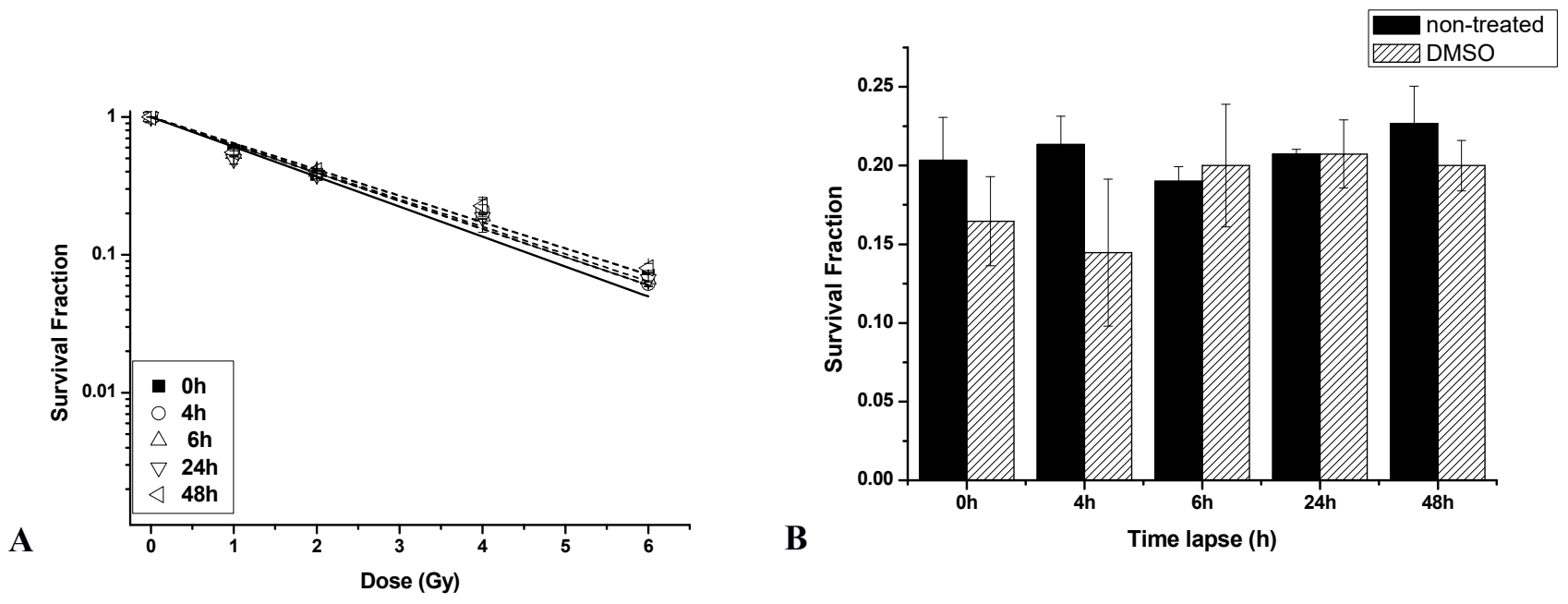


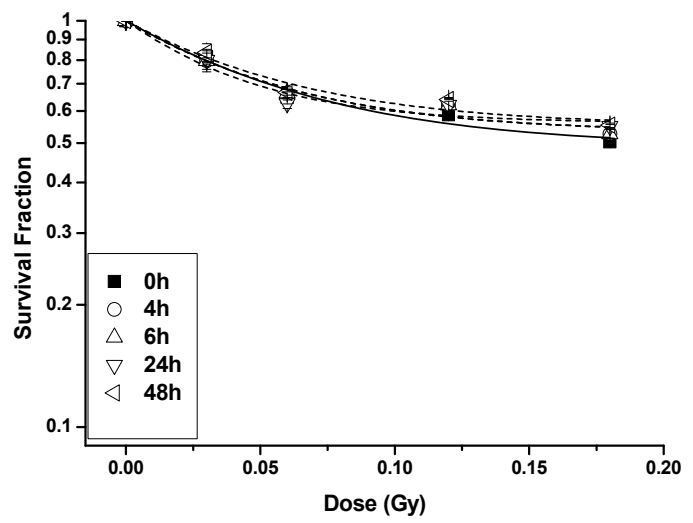

C

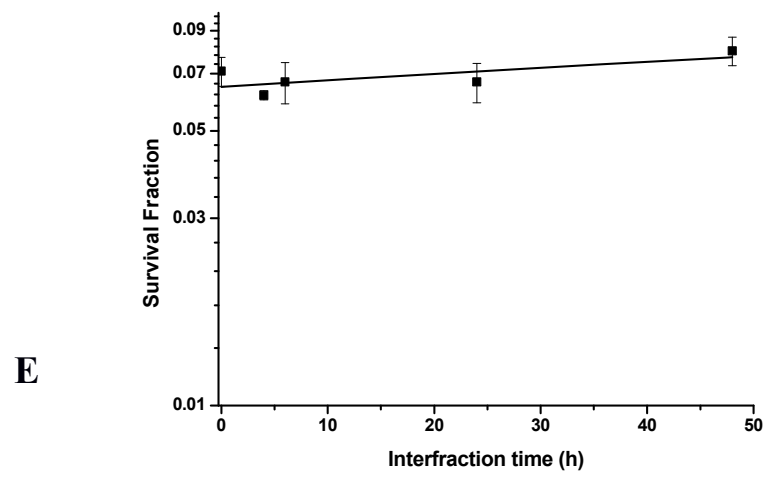

Figure 4.

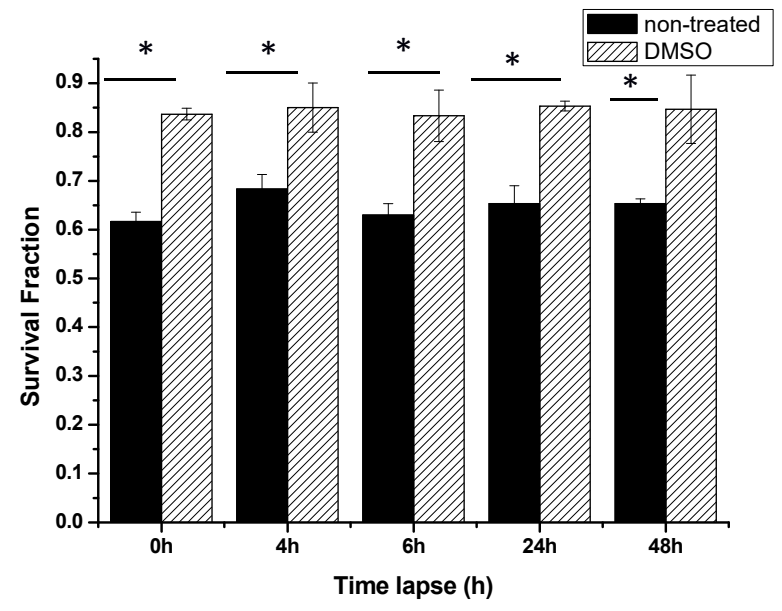




\begin{tabular}{ccccc}
\hline Uniform Field & \multicolumn{2}{c}{ MCF-7 } & \multicolumn{2}{c}{ AGO-1522 } \\
\hline Time lapse (h) & $\alpha\left(\mathrm{Gy}^{-1}\right)$ & $\beta\left(\mathrm{Gy}^{-2}\right)$ & $\alpha\left(\mathrm{Gy}^{-1}\right)$ & $\beta\left(\mathrm{Gy}^{-2}\right)$ \\
$\mathbf{0}$ & $0.29 \pm 0.1$ & $0.06 \pm 0.03$ & $0.71 \pm 0.08$ & $0.02 \pm 0.02$ \\
$\mathbf{4}$ & $0.27 \pm 0.02$ & $0.04 \pm 0.01$ & $0.69 \pm 0.07$ & $0 \pm 0.02$ \\
$\mathbf{6}$ & $0.26 \pm 0.03$ & $0.04 \pm 0.01$ & $0.7 \pm 0.08$ & $0 \pm 0.02$ \\
$\mathbf{2 4}$ & $0.26 \pm 0.03$ & $0.04 \pm 0.01$ & $0.65 \pm 0.05$ & $0 \pm 0.01$ \\
$\mathbf{4 8}$ & $0.29 \pm 0.05$ & $0.03 \pm 0.01$ & $0.64 \pm 0.04$ & $0 \pm 0.01$ \\
& In-field & & Modulated field & \\
$\mathbf{0 h}$ & $0.35 \pm 0.1$ & $0 \pm 0.02$ & $0.45 \pm 0.06$ & $0.02 \pm 0.01$ \\
$\mathbf{4 h}$ & $0.3 \pm 0.1$ & $0 \pm 0.01$ & $0.46 \pm 0.01$ & $0 \pm 0.02$ \\
$\mathbf{6 h}$ & $0.28 \pm 0.02$ & $0 \pm 0.01$ & $0.46 \pm 0.07$ & $0 \pm 0.01$ \\
$\mathbf{2 4 h}$ & $0.2 \pm 0.01$ & $0 \pm 0.06$ & $0.49 \pm 0.02$ & $0 \pm 0.01$ \\
$\mathbf{4 8 h}$ & $0.2 \pm 0.02$ & $0 \pm 0.01$ & $0.43 \pm 0.08$ & $0 \pm 0.01$ \\
\hline
\end{tabular}

Table 1. 


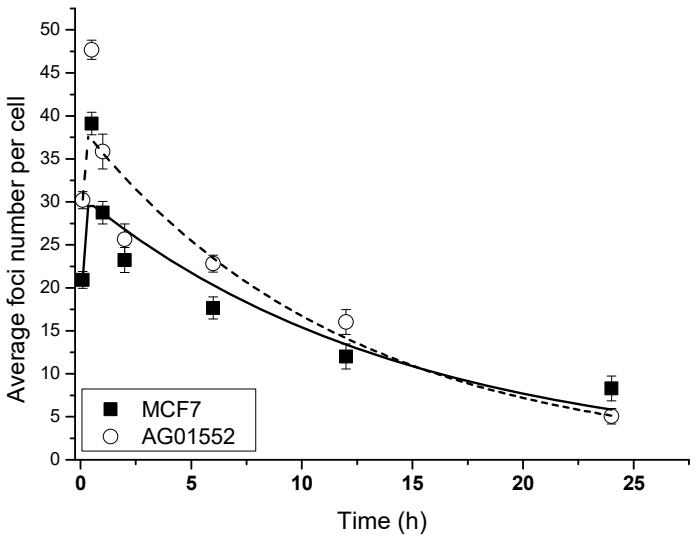

A

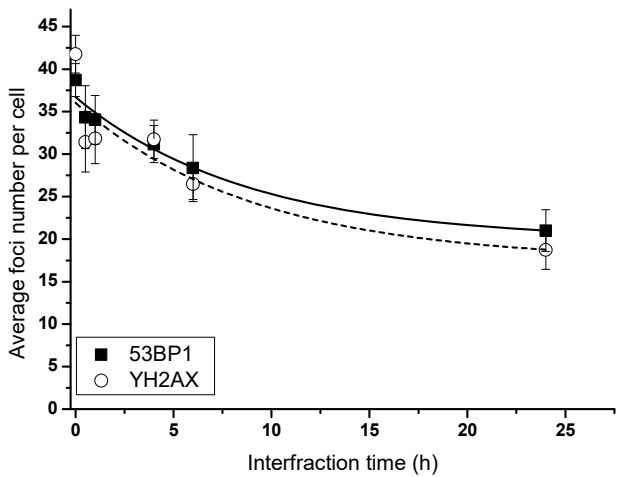

C

Figure 5. 


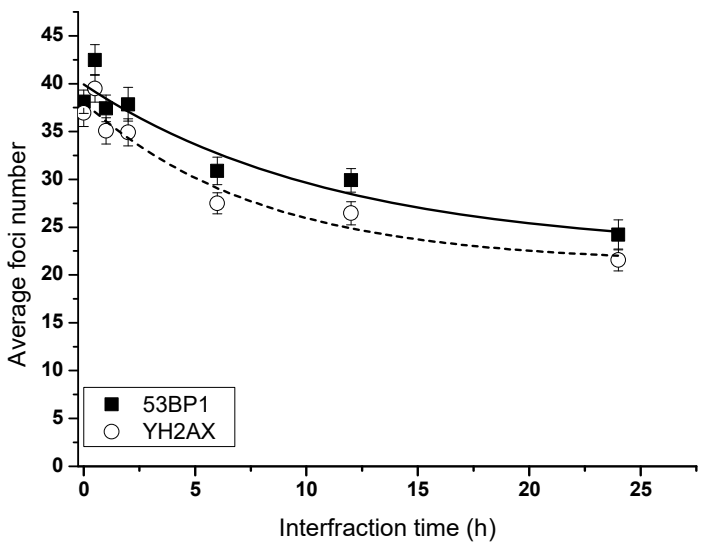




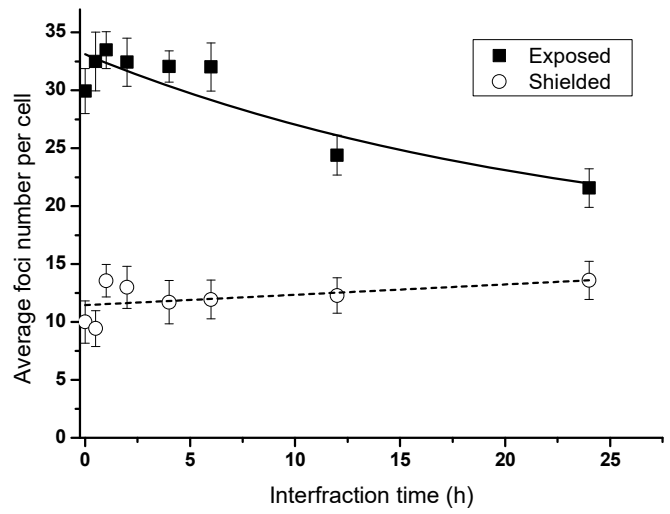

A

Figure 6.

A 


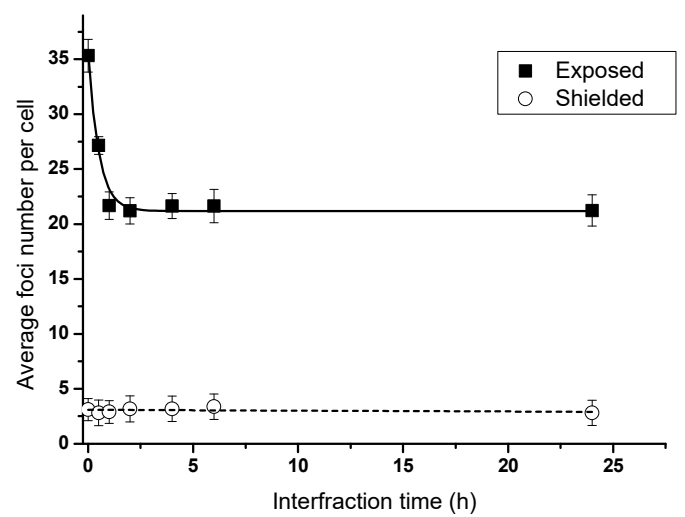

B 
A

\begin{tabular}{ccc}
\hline Cell line & $\begin{array}{c}\text { DNA } \\
\text { damage } \\
\text { decay rate } b \\
\left(\mathrm{~h}^{-1}\right)\end{array}$ & $\begin{array}{c}\mathbf{t}_{1 / 2} \text { repair half time } \\
\text { from DNA damage }\end{array}$ \\
repair
\end{tabular}

(h)

\begin{tabular}{ccc}
\hline $\begin{array}{c}\text { MCF-7 } \\
\text { single dose }\end{array}$ & $0.153 \pm 0.01$ & $4.52 \pm 0.5$ \\
$\begin{array}{c}\text { AGO-1522 } \\
\text { single dose }\end{array}$ & $0.117 \pm 0.03$ & $5.92 \pm 0.8$ \\
\hline
\end{tabular}

B

\begin{tabular}{cccccc}
\hline Cell line & $\begin{array}{c}y_{0}(\text { foci } \\
\text { induced by } \\
\text { the second } \\
\text { fraction) }\end{array}$ & $\begin{array}{c}\text { A (foci } \\
\text { induced by } \\
\text { the first } \\
\text { fraction) }\end{array}$ & $\begin{array}{c}\text { decay rate } b \\
\left(\mathrm{~h}^{-1}\right)\end{array}$ & $\begin{array}{c}\mathbf{t}_{1 / 2} \text { repair half time } \\
\mathbf{t}_{1 / 2} \text { recovery half time } \\
\text { from survival } \\
\text { recovery kinetics }\end{array}$ & (h)
\end{tabular}

(h)

\begin{tabular}{cccccc}
\hline $\begin{array}{c}\text { MCF-7 } \\
\text { uniform }\end{array}$ & $22.43 \pm 4.4$ & $17.48 \pm 4.16$ & $0.17 \pm 0.03$ & $4.07 \pm 0.5$ & $4.06 \pm 1.08$ \\
$\begin{array}{c}\text { AGO-1522 } \\
\text { uniform }\end{array}$ & $17.42 \pm 5.4$ & $18.59 \pm 5.28$ & $0.10 \pm 0.05$ & $6.93 \pm 0.8$ & $4.94 \pm 0.2$ \\
$\begin{array}{c}\text { MCF-7 } \\
\text { exposed }\end{array}$ & $0.8 \pm 0.8$ & $33.26 \pm 8.23$ & $0.08 \pm 0.05$ & $9.9 \pm 0.9$ & $5.46 \pm 1.43$ \\
$\begin{array}{c}\text { AGO-1522 } \\
\text { exposed }\end{array}$ & $21.18 \pm 0.5$ & $14.47 \pm 1.19$ & $1.9 \pm 0.07$ & $0.5 \pm 0.12$ & \\
\hline
\end{tabular}

Table 2. 
